\title{
ИНВЕСТИЦИОННАЯ ПОЛИТИКА ШВЕЙЦАРИИ В РОССИИ ДО И ПОСЛЕ ВВЕДЕНИЯ САНКЦИЙ
}

\begin{abstract}
Аннотация. Статья посвящена специфике швейцарских инвестиций в России, сформировавшейся до введения санкций в отношении России, а также после присоединения Швейцарии к ним. Автор рассматривает и анализирует группы факторов, повлиявших на инвестиционную стратегию Швейцарии в России. Выделяются особенности этой стратегии, в первую очередь связанные со структурой швейцарских инвестиций, их “нишевым” характером и традиционной специализацией, отраслевой ориентацией и региональным распределением. На основе анализа и обобщения статистических данных центральных банков РФ и Швейцарии, международных организаций, а также исследований российских и зарубежных авторов, выявлены динамика и изменение структуры швейцарских инвестиций в России. Использован метод сравнительного анализа, в том числе для данных по отдельным европейским странам, что позволяет выделить периоды, характеризующиеся как ростом, так и падением европейских и швейцарских инвестиций. Автор приходит к выводу, что, несмотря на санкции, Россия остаётся в сфере интересов Швейцарии. Динамика притока её прямых инвестиций в целом положительна. Швейцарские компании продолжают инвестировать в российскую экономику, в том числе используя процесс локализации производства в отдельных отраслях и швейцарские технологии.
\end{abstract}

Ключевые слова: прямые и портфельные инвестиции, Швейцария, санкции, структура инвестиций, распределение инвестиций по регионам и отраслям.

Анализ российско-швейцарского инвестиционного сотрудничества имеет важное значение, так как Швейцария, крупнейший европейский и международный инвестор, поддерживает связи с Россией во всех сферах экономики и политики. Комплексных научных исследований деятельности швейцарских компаний в России, инвестиционной стратегии Швейцарии как до, так и после введения санкций очень мало.

(c) Трофимова Ольга Ефимовна - к.э.н., старший научный сотрудник Центра европейских исследований, Национальный исследовательский институт мировой экономики и международных отношений имени Е.М. Примакова РАН. Адрес: 117997 , Россия, Москва, ул. Профсоюзная, д. 23. E-mail: olgatrofimova53@mail.ru

Данная статья подготовлена по гранту РНФ 14-28-00097 “Оптимизация российских внешних инвестиционных связей в условиях ухудшения отношений с ЕС” в Институте мировой экономики и международных отношений РАН.

DOI: http://dx.doi.org/10.15211/soveurope62018123133 
Присоединение Швейцарии к санкциям в отношении России, но с большими оговорками, практически не сказалось на динамике инвестиционных связей двух стран, которые в целом носят позитивный характер. Среди европейских партнёров России Швейцария занимает особое положение - против неё контрсанкции не были введены. Швейцарские компании планируют и далее инвестировать в отрасли с весомым потенциалом роста, такие как фармацевтика и электротехника. При этом все большее число этапов производства переносится в Россию, постепенно происходит локализация производства. Это связано с тем, что большинство проектов швейцарские компании рассматривают с точки зрения долгосрочных инвестиций. Кроме того, нейтральный статус и прагматичный подход к внешним проблемам позволяют стране проводить независимую внешнеэкономическую политику [Кузнецов В.А., 2013].

Обесценение рубля оказало негативное влияние на экспорт из Швейцарии, но сделало инвестиции в России более привлекательными для швейцарских компаний, которые помимо традиционных сфер сотрудничества стали присматриваться к таким перспективным секторам, как медицинские технологии, гражданская авиация и судостроение. Так, доля Швейцарии в прямых иностранных инвестициях (ПИИ) в России после падения в 2015 гг. (в абсолютном выражении) выросла с 3\% в 2016 г. до 5,2\% в 2017 г. на фоне снижения доли стран ЕС [данные ЦБ России].

\section{Инвестиционное сотрудничество двух стран: факторы влияния}

После введения санкций против России в 2014 г., падения цены на нефть и как следствие ухудшения экономической ситуации в РФ приток иностранных инвестиций снизился, особенно в 2015 г. [Оптимизация, 2016: 30] Такая динамика отразила рост рисков для иностранных инвесторов в России, из-за которых некоторые из них ушли с российского рынка. Но основная часть иностранных компаний осталась, в том числе швейцарские.

В докладе британской консалтинговой компании Global Counsel в 2016 г. отмечалось снижение интереса крупных ТНК к инвестированию в Россию после введения санкций. Однако оно не коснулось такой отрасли, как фармацевтическая, которая является одной из приоритетных для швейцарских инвестиций. Вложения в рублевые активы сократились на фоне падения цен на нефть, но большинство компаний осталось на российском рынке. Более пессимистично настроены финансовые и сырьевые компании, которые несут потери после введения санкций. С конца 2016 г. наблюдается рост инвестиций в Россию, особую активность стали проявлять азиатские страны.

Крупный российский рынок привлекает компании Швейцарии, особенно для создания предприятий обрабатывающей промышленности с возможным использование своих ноу-хау. Этому способствует традиционная стратегия швейцарских компаний по географической диверсификации своей деятельности. Швейцария входит в первую десятку основных инвесторов России. Несмотря на санкции, к которым она присоединилась с оговорками, её подход к сотрудничеству с Россией носит продуманный характер, имеются реальные перспективы для развития инвестиционного сотрудничества двух стран. 
Таблица 1.

Приток прямых иностранных инвестиций в Россию в 2007-2017 гг. (в млн долл. и в \% от общего притока, по методологии платёжного баланса)

\begin{tabular}{|l|c|c|c|c|c|}
\hline & Все страны & Европа & Германия & Франция & Швейцария \\
\hline 2007 г. & 65800 & 33900 & $7600(11,5 \%)$ & $415(0,7 \%)$ & $386(0,6 \%)$ \\
\hline 2009 г. & 36600 & 19900 & $2900(7,9 \%)$ & $696(1,9 \%)$ & $1900(5,2 \%)$ \\
\hline 2011 г. & 55000 & 43000 & $2200(4,0 \%)$ & $1100(2,0 \%)$ & $741(1,3 \%)$ \\
\hline 2013 г. & 69200 & 60400 & $335(0,5 \%)$ & $2121(3,0 \%)$ & $1086(1,6 \%)$ \\
\hline 2014 г. & 22000 & 9700 & $349(1,5 \%)$ & $2224(10.0 \%)$ & $2476(11,3 \%)$ \\
\hline 2015 г. & 6850 & -5200 & $1480(21,7 \%)$ & $1686(25,0 \%)$ & $203(3,0 \%)$ \\
\hline 2016 г. & 32500 & 5400 & $274(0,8 \%)$ & $438(1,3 \%)$ & $1000(3,0 \%)$ \\
\hline 2017 г. & 28700 & 17700 & $470(1,6 \%)$ & $854(2,9 \%)$ & $1500(5,2 \%)$ \\
\hline
\end{tabular}

Источник: составлено и рассчитано по данным Банка России (Прямые инвестиции в РФ: операции по экономическим и географическим зонам). Режим доступа: http://www.cbr.ru/statistics/?PrtId=svs

Как видно из таблицы 1, приток ПИИ из Швейцарии в Россию в 2007-2017 гг. был сопоставим с их притоком из Германии и Франции. Даже в условиях санкций французские и германские компании продолжают инвестировать в российские регионы, несмотря на общее снижение притока капитала из европейских стран. В 2016-2017 гг. Россия занимала 10-е место по притоку ПИИ в мире. [World Investment Report, 2018:4]. Наиболее стабильными остаются ПИИ из Швейцарии, они выросли в 2017 г. по сравнению с некоторыми странами ЕС (табл. 1). По данным ЦБ, они составили 5,2\% от притока всех ПИИ в России, а по данным Росстата $5,7 \%$ [Инвестиции в России, 2017]. Это было связано с менее жёсткой позицией Швейцарии, не входящей в ЕС, относительно введения санкций.

На инвестиции Швейцарии в РФ в 2000-е гг. оказали влияние несколько групп факторов. Первая имеет общий характер и влияет в целом на инвестиционные связи России со всеми странами. Её экономика, несмотря на определённую модернизацию, имеет сырьевую направленность, зависит от динамики цен на нефть, отличается невысокой наукоёмкостью. Недостаточно благоприятные условия для развития малого и среднего бизнеса тормозят приток инвестиций из Швейцарии, где малый и средний бизнес играет важную роль в экономике.

Модернизация и диверсификация экономики России с курсом на инновации и улучшение качества человеческого капитала, создание новых конкурентных преимуществ дали толчок притоку швейцарских инвестиций на российский рынок и способствовали переносу все большего числа этапов производства и создания цепочек производства. Мотивом размещения производственных площадок швейцарскими компаниями в России является повышение конкурентоспособности продукции за счёт низких налогов, наличие особых экономических зон и возможность использовать создаваемые производства для выхода на рынки третьих стран. 
Вторая группа факторов связана с особенностями швейцарской экономической модели. Для Швейцарии характерна высокая доля инновационного сектора в экономике. В 2017 г. она была в шестой раз признана самой инновационной страной в мире по версии института INSEAD и Всемирной организации интеллектуальной собственности [Global Innovation Index, 2018]. Экономический успех Швейцарии можно объяснить и её особым подходом к балансу между рынком и государством; стремлением согласовать с международным окружением внутренние потребности, а также гибкими рыночными механизмами [Y. Guo and J. Woo, 2016].

Экономический успех Швейцарии базировался на трёх факторах: науке, образовании и высоких технологиях. Широкое внедрение цифровых технологий стало важным направлением развития её экономики. Конкурентными преимуществами являются сфера услуг (70\% ВВП страны), квалифицированная рабочая сила и банковский сектор [Европейская интеграция, 2011]. В Швейцарии развиты машиностроение, химическая промышленность и ряд нишевых отраслей, таких как высокоточная механика и фармацевтика. В стране имеются как крупные компании транснационального характера (“Нестле”, “Новартис”, “Хоффман-ля-Рош”, “Асеа Браун Бовери” (АББ), “Алюсюисс" и др.), так и средние и малые компании, число которых составило в 2016 г. более 560 тыс. [Годовой обзор, 2017]. На них приходилось 99,8\% всех компаний Швейцарии в 2016 г. [Swiss Federal, 2017:17]. Развитие этих компаний является важным национальным проектом, поддерживается государством.

Особенность швейцарской бизнес-инфраструктуры состоит в построении по принципу объединения в кластеры малого и среднего бизнеса смежных областей, расположенных в территориальной близости. Этому способствовали децентрализация экономики, федеративное устройство страны и самостоятельность отдельных кантонов. [Авраменко С.Л.] В настоящее время в Швейцарии насчитывается более 20 кластеров. Самые крупные это кластеры биотехнологий, информационных технологий, финансовый и МЭМ-кластер (машиностроительные, энергетические и металлообрабатывающие компании). В МЭМ-кластере работают более 14500 компаний, их экспорт составляет 30\% от общего экспорта страны [Структура, 2017].

В 2015-2016 гг. Швейцария занимала третье место в мире по доступности финансовых услуг. Там находятся около 270 банков и 200 страховых компаний, а финансовые объединения “Ю Би Эс" и “Креди Суисс" входят в первую шестёрку в банковском бизнесе. Конфиденциальность вложений капитала, стабильная денежная система, низкий уровень инфляции - всё это привлекает международных клиентов [Benediktes, Kaelin, 2013]. Соблюдение жёстких стандартов банковской деятельности укрепляет доверие к швейцарским банкам, особенно во время кризисов [Б. Дегарден, 2013].

Третья группа факторов, повлиявших на приток швейцарских инвестиций в Россию, это внешние факторы. К ним относятся: мировой финансовый и экономический кризис 2008-2009 гг., ухудшение международной политической ситуации, резкое падение цен на нефть, а также антироссийские санкции. Эти факторы не являются постоянными, они имеют конъюнктурный характер. Частичное присоединение к санкциям Швейцария объясняет тем, что без этих мер её территорию использовали бы для обхода санкций, в том числе страны ЕС. Первоначально в список попали пять российских банков, несколько компаний и 11 физических лиц.

Современная Европа, 2018, №6 
Швейцария также запретила импорт материалов военного назначения и ограничила инвестиции в Крыму. При этом все швейцарские компании продолжили работать на российском рынке.

В первую очередь санкции привели к снижению оборотов торговли и туристического бизнеса. В 2015 г. экспорт часов из Швейцарии в Россию упал на 32,6\%, по сравнению с 2014 г. [Годовой обзор, 2017]. Был пересмотрен контракт фирмы “Стадлер" с российским предприятием “Аэроэкспресс": из-за падения курса рубля и цен на нефть стоимость на поставки поездов выросла на $30 \%$.

\section{Специфика инвестиционной экспансии}

Швейцария входит в десятку крупнейших экспортёров иностранных прямых инвестиций. В начале 2000-х гг. Швейцария занимала пятое место в Европе по объёму накопленных ПИИ (250 млрд долл.) [Государства Альпийского региона, 2009: 206]. В 2017 г. он составил 1271,7 млрд долл., тогда как накопленные ПИИ стран ЕС достигли 10631 млрд долларов. [World Investment Report 2018: 188].

Инвестиционная стратегия Швейцарии в России имеет ряд особенностей. Вопервых, это инвестирование не в сырьевую, а в обрабатывающую промышленность: высокоточное машиностроение; ресурсосберегающие, энергоэффективные технологии и наукоёмкие отрасли. Во-вторых, это высокая доля прямых инвестиций и кредитов в общем инвестиционном потоке. В-третьих, часть инвестиционных проектов в России реализуется малыми и средними предприятиями, но локализация идёт за счёт крупных. В-четвёртых, швейцарские компании создают как совместные предприятия в России, так и предприятия со $100 \%$ участием, когда производства на местах опираются на использование швейцарских технологий. В-пятых, усиление турбулентности в условиях санкций. Так, многоотраслевой концерн “Зальцер АГ”, где контрольный пакет принадлежал российской “Ренова", оказались под угрозой блокировки деятельности. Компания В. Вексельберга вынуждена была сократить свою долю ниже контрольной, чтобы вывести швейцарскую компанию и свои активы из-под санкций. В-шестых, Швейцария до последнего времени относилась к странам, через которые в Россию шли из третьих стран ПИИ, путешествующие по кругу, в то время как Германия и Франция относятся к источникам "настоящих" ПИИ в РФ [Оптимизация, 2016: 9].

Выделяются три основные группы швейцарских инвестиций в Россию: 1) масштабные капиталовложения крупных компаний (фармацевтика, пищевая, специализированное машиностроение); 2) инвестиции небольших компаний, не всегда связанные с традиционной специализацией (металлургия, нефтегазовый комплекс, производство удобрений, деревообработка), а также компаний, желающих подключиться к прибыльному и иногда рискованному бизнесу; 3) портфельные инвестиции, которые иногда могут переходить в прямые после приобретения дополнительных пакетов акций, в основном это институциональные инвесторы [Европейские инвестиции, 2006].

В 2000-е гг. сложившаяся структура швейцарских инвестиций в Россию практически не изменилась. Но в определённые периоды их приток по отдельным группам значительно колебался. Так, в 2011 г. из 191 млрд долл. иностранных инвестиций в Россию 83 млрд долл. составляли краткосрочные кредиты из Швейцарии [иностранствующие инвестиции]. Они не нашли отражения в статистике накопленСовременная Европа, 2018, №6 
ных инвестиций, так как представляли собой краткосрочные вложения в виде кредитов, погашаемых в течение трёх-шести месяцев.

Объём накопленных прямых инвестиций Швейцарии в РФ на начало 2015 г. составлял, по данным Банка Швейцарии, 9,47 млрд долл., а в 2016 г. он вырос до 11,25 млрд. На них приходилось около $1 \%$ всех ПИИ Швейцарии в 2016 г. $(0,7 \%$ в 2007 г.), для сравнения: на Россию приходилось 2,1\% всех накопленных ПИИ ЕС по данным Евростат [Eurostat Newsrelease, 2017]. На начало 2018 г. накопленные прямые инвестиции Швейцарии в РФ достигли 12,8 млрд долл., Франции - 15,1 млрд, Германии - 18,1 млрд долл. [данные Банка России].

Таблица 2.

Объём накопленных прямых инвестиций Швейцарии (в млн долл.)

\begin{tabular}{|l|c|c|c|c|c|c|c|}
\hline & 2007 г. & 2009 г. & 2011 г. & 2013 г. & 2014 г. & 2015 г. & 2016 г. \\
\hline $\begin{array}{l}\text { Общий } \\
\text { объём всех } \\
\text { накопленных } \\
\text { инвестиций }\end{array}$ & 917700 & 962610 & 924521 & 990234 & 993127 & 1079866 & 1202575 \\
\hline $\begin{array}{l}\text { Накопленные } \\
\text { инвестиции } \\
\text { в странах ЕС }\end{array}$ & 397780 & 414160 & 402690 & 429750 & 451100 & 538358 & 627957 \\
\hline $\begin{array}{l}\text { Накопленные } \\
\text { инвестиции } \\
\text { в России } \\
\text { Данные ЦБ } \\
\text { Швейцарии) }\end{array}$ & 6653 & 6760 & 9802 & 13967 & 9856 & 9470 & 11474 \\
\hline $\begin{array}{l}\text { Накопленные } \\
\text { инвестиции } \\
\text { в России } \\
\text { (данные Бан- } \\
\text { ка России) }\end{array}$ & - & 5688 & 5679 & 6834 & 10595 & 8619 & 11259 \\
\hline
\end{tabular}

Источник: составлено по данным ЦБ Швейцарии и Банка России. Данные в швейцарских франках пересчитаны в доллары по среднегодовому курсу. Swiss National Bank data Statistics. International economic affairs. Direct investment abroad. 2016, 2016-12-16 URL: https://data.snb.ch/en/topics/aube\#!/cube/fdiausbla?fromDate=2007\&toDate=2016\&dimSel=d0(T 0,T1,RU,B3,T2,T4,T5,T6), данным ЦБ России: (http://www.cbr.ru/statistics/?Prtid=svs)

Число инвестиционных проектов Швейцарии в России после некоторого снижения постепенно растёт. Из 238 проектов в 2017 г. на Германию приходилось 28, на Францию и Швейцарию по 11. При этом зарубежные инвесторы вкладывают средства в развитие новых производств, а не в расширение существующих. [Исследование инвестиционной привлекательности 2018: 4].

\section{Особенности отраслевого распределения швейцарских инвестиций}

По данным швейцарской статистики, свои штаб-квартиры в России имеют 150 компаний, около 200 компаний зарегистрированы при Швейцарском центре содействия бизнесу. Там работает 75 тыс. человек. $45 \%$ это предприятия со $100 \%$ швейцарским капиталом [Белов, 2014: 103]. По российским данным их число дос- 
тигает 600 с учётом тех, кто работает в РФ без физического присутствия. Инвестиции Швейцарии в России сосредоточены в пищевой, фармацевтической промышленности, в производстве строительных материалов, агробизнесе и машиностроении. На конец 2017 г. в обрабатывающие отрасли швейцарские компании инвестировали 4452 млн долл., в горнодобывающую промышленность - 1417 млн, в оптовую торговлю и ремонт оборудования - 960 млн, в финансы и страхование 506 млн долл. [данные Банка России].

Для банков, страховых и инвестиционных обществ привлекательность российского финансового сектора и интенсивность сотрудничества с российскими структурами в последние годы снизились из-за волатильности рубля и экономической нестабильности. В России присутствуют несколько инвестиционных банков "Ю Би Эс”, “Креди Суисс”, “Ломбар Одье”, “Хофман” и др. В основном они занимаются посреднической деятельностью, предоставляют услуги на российском фондовом рынке, осуществляют управление активами и т.п.

Основным швейцарским инвестором в пищевой отрасли России является концерн "Нестле". Его стратегия направлена на локализацию производства и его региональную диверсификацию. Первые инвестиции компании были осуществлены в 1992 г. путём покупки пакета акций самарской кондитерской фабрики “Россия". После приобретения в конце 1990-х гг. трёх кондитерских предприятий в Самаре, Барнауле и Перми доля "Нестле" в производстве шоколада в России выросла до 1/6 [Европейские инвестиции, 2006: 139]. С 1996 г. по 2015 г. инвестиции компании в РФ достигли 1,85 млрд долл., а в 2016 г. продажи выросли на 5,5\% по сравнению с предыдущим годом, несмотря на падение реальных доходов россиян и сложную экономическую ситуацию. "Нестле" имеет в России 12 предприятий и девять региональных офисов (в Санкт-Петербурге, Ростове-на-Дону, Екатеринбурге, Новосибирске, Владивостоке, Иркутске, Воронеже, Нижнем Новгороде и Самаре). Общее число занятых составляет около 5500 человек [Ventes, 2016]. В 2017 году "Нестле" инвестировала 6,4 млрд руб. в российскую экономику за счёт развития локального производственного потенциала.

Крупным проектом является фабрика "Нестле Пурина ПетКер" в Калужской области, где в ноябре 2017 г. были открыты две линии по производству кормов для домашних животных. Инвестиции в расширение производства составили 4 млрд руб., а с момента открытия предприятия в 2006 г. они достигли 16 млрд руб. [Инвестиционный портал регионов, 2017]. Второй проект - строительство нового завода полного цикла по производству детского питания в Вологде. Компания планирует вложить в него 1,8 млрд рублей в 2017-2019 гг.

Штат компании АББ (Asean Brown Boveri), специализирующейся в сфере электротехники, энергетического машиностроения и информационных технологий, насчитывает в России более 1300 сотрудников. Компания имеет семь производственных и 12 сервисных площадок в Москве, Московской области, Санкт-Петербурге, а также 28 региональных офисов.

В июне 2015 г. был открыт построенный АББ с нуля первый завод по производству низковольтных электротехнических оболочек в особой экономической зоне “Липецк”. Инвестиции в проект составили 20 млн долл. В 2016 г. Минэкономразви- 
тия одобрило новый проект АББ по строительству в Липецке второго завода с сопоставимым объёмом инвестиций.

Наиболее перспективной для инвестирования отраслью в России считается фармацевтическая, на ней практически не сказалось введение санкций. Стратегия Швейцарии в сфере фармацевтики диверсифицирована и заключается в построении новых заводов, передаче технологий и распространении готовой продукции через местных дистрибьюторов. Крупная фармацевтическая компания "Новартис" видит большие перспективы и выгоды в России от локализации производства. Она построила первый завод полного цикла в Санкт-Петербурге в 2017 г. На предприятии будут выпускаться 40 наименований препаратов и разрабатываться отечественные медицинские препараты как оригинальные, так и дженерики. Общий объём инвестиций составит 500 млн долл. [сайт компании "Новартис"]. За девять месяцев 2017 г. продажи “Новартис" в России выросли на 2\%.

Компания "Хофман-ля-Рош" также выпускает ряд медицинских препаратов в рамках проекта с российским Минздравом и будет участвовать в выпуске противоопухолевых препаратов на заводе “Фармстандарт-Уфавита": она инвестирует 1,5 млрд руб. в трансфер технологий, обучение персонала, организацию системы контроля качества и логистику. В 2017 г. компания подписала соглашение с медицинским университетом имени И.М. Сеченова о разработке лекарств с нуля и проведении совместных фундаментальных исследований. Инвестиции в проект в первый год составят 50 млн рублей.

К локализации своего производства приступила с августа 2016 г. швейцарская компания “Ферринг Фармасьютикалс". В августе 2016 г. она договорилась о локализации производства инновационных лекарственных препаратов на заводе "Фармстандарт-Уфавита". Производство инъекционных лекарственных средств полного цикла в перспективе позволит наладить экспорт препаратов в другие страны.

Швейцарская компания "Холсим" инвестирует в цементную промышленность России с 1993 г. После слияния "Холсим” с французской “Лафарж” в 2015 г. эта группа контролирует $10 \%$ производства цемента в России. Её инвестиции в России составили 1,3 млрд швейц. франков. В Московской и Саратовской областях, где "Холсим" имеет два завода, они достигли 900 млн евро [Investment Project, 2014].

В 2013 г. в России на базе "Савеловского машиностроительного завода" было создано первое российско-швейцарское СП по производству металлообрабатывающих станков промышленной корпорацией “Оборонпром” вместе с группой компаний "Георг Фишер Групп", куда входит швейцарская компания "ГФ АжиШармий”. В 2011 г. в Нижегородской области было введено в эксплуатацию первое дочернее предприятие корпорации “Либхерр" - ООО “Либхерр-Нижний Новгород” по производству и сборке строительной техники, комплектующих частей, основных компонентов для систем управления полётов. Инвестиции Швейцарии составили 272 млн долларов. [Инвестиционный портал регионов, 2017].

Концерн “Шиндлер”, крупный производитель лифтов, ещё в 2002 г. приобрёл $51 \%$ российского акционерного общества “Лифтремонт”. Его инвестиции в Москве составили 300 млн евро. “Суотч Групп”, производитель часов во всех ценовых сегментах, имеет пять специализированных магазинов в России. Логистическая швейцарская компания "Кюхне+Нагель" открыла в 2016 г. несколько логистических

Современная Европа, 2018, №6 
центров и планирует довести их число до 18. Инвестиции компании “Кроно” в деревообрабатывающую отрасль Костромской области составили более 350 млн евро [Investment Projects, 2014].

Крупным инвестором, не связанным с традиционной специализацией Швейцарии, является сырьевой трейдинговый холдинг “Гленкор”. С 2007 г. он имеет 8,75\% в объединенной компании "РУСАЛ”. В начале 2000 -х гг. "Гленкор" предоставила для создания компании “Русснефть” кредиты под залог акций добывающих предприятий. После многочисленных реструктуризаций “Русснефти" "Гленкор" получила в 2015 г. $46 \%$ уставного капитала компании, а затем в августе 2016 г. снизила её до $25 \%$.

Региональное распределение швейцарских инвестиций отражает их отраслевую специфику, связанную с предпочтительным инвестированием в обрабатывающую промышленность. Размещение представительств, собственных и совместных производств в Центральном, Приволжском, Северо-Западном и Уральском федеральных округах связано с их регистрацией преимущественно в основных финансовых и производственных центрах России, наличием квалифицированной рабочей силы и платежеспособного населения, крупных научных центров, логистических и дистрибьютерских цепочек, развитой инфраструктуры.

Отсутствие полных данных по региональному распределению швейцарских инвестиций не позволяет сделать точный вывод об изменении или сохранении существующих тенденций. В 2013 г. на швейцарские компании приходилось 94,6\% всех иностранных инвестиций в Тульской области, 55,3\% - во Владимирской области, $68,2 \%$ - в Рязанской области, 92,6\% - в республике Мордовия, $15,8 \%$ - в Томской области и более чем по $8 \%$ в Челябинской и Оренбургской областях [Прямые иностранные, 2014]. В 2017 г. Швейцария участвовала в четырёх инвестиционных проектах в Московском регионе [Исследование инвестиционной привлекательности, 2018].

Инвестиционное сотрудничество двух стран продолжает развиваться, несмотря на колебания в притоке швейцарского капитала в Россию из-за конъюнктурных и циклических факторов и санкций. В целом динамика инвестирования имела положительную тенденцию, наметился процесс локализации производств. Швейцария остаётся важным источником капитала для России. Её инвестиционная стратегия на российском рынке связана с особенностями развития национальной промышленности, включая нишевую специализацию, дигитализацию экономики и географическую диверсификацию. Для Швейцарии характерна высокая доля ПИИ и кредитов в структуре инвестиций, ориентация на обрабатывающую промышленность. Влияние западных санкций выразилось в общей неблагоприятной экономической ситуации в России и сказалось на притоке иностранных инвестиций из Европы и США. Но прагматичная инвестиционная стратегия и сложившаяся структура швейцарских инвестиций позволила сгладить их негативные последствия. О привлекательности России свидетельствует тот факт, что при посольстве Швейцарии функционирует один из 22 швейцарских Центров содействия бизнесу, и ни одна швейцарская компания не покинула Россию, что во многом связано с их деятельностью в менее затронутых санкциями отраслях и независимой внешнеэкономической политикой. 


\section{Список литературы} $177 \mathrm{c}$.

Авраменко С.Л. (2003) Швейцарский федерализм на рубеже столетия. МГИМО Университет.

Белов Н.И. (2014) Современное состояние российско-швейцарских торгово-экономических отношений // Российский внешнеэкономический вестник. №12, С. 97-107.

Годовой обзор экономики и основных направлений внешнеэкономической деятельности Швейцарской Конфедерации в 2016 году. (2017) г. Берн, апрель 2017 г. 148 с.

Государства Альпийского региона и страны Бенилюкс в меняющейся Европе (2009) (Под ред. Швейцера В.Я.) М.: Изд-во “Весь Мир”. 544 с.

Данные Банка России. [Электронный ресурс] URL: http://www.cbr.ru/statistics/?PrtID=svs (дата обращения 10.09.2018).

Дегарден Б. (2013) Феномен банковской системы Швейцарии. Исторические факты и современные тенденции развития. Избранные лекции Университета. Изд-во Санкт-Петербург СПбГУП 201345 с.

Европейская интеграция (2011) (под редакцией д.э.н. О.В. Буториной). Издательский дом “Деловая литература". 720 с.

Европейские прямые инвестиции в России. (2006). Под редакцией д.э.н. А. Кузнецова. Москва. ИМЭМО РАН. 133 с.

Инвестиции в России. 2017: Стат. Сборник. (2017) М. Росстат. 188 с.

Инвестиционный портал регионов России. [Электронный ресурc] URL:

https://www.investinregions.ru/success/Liebherr-Nizhny-Novgorod/ (дата обращения 03.11.2017).

Иностранствующие инвестиции [Электронный ресурс] URL:

https://www.kommersant.ru/doc/1883823 (дата обращения 12.10.2017).

Исследование инвестиционной привлекательности стран Европы. Россия 2018 г. (2018) Эрнст энд Янг. $8 \mathrm{c.}$

Оптимизация инвестиционных связей современной России. (2016) Под редакцией членакорреспондента РАН А. В. Кузнецова. Москва. ИМЭМО РАН. 120 с.

Прямые иностранные инвестиции в Россию: региональный аспект. Аналитический обзор 1 апреля 2014. (2014) Национальное рейтинговое агентство. 15 с.

Сайт компании "Новартис" [Электронный ресурc] URL: http://www.novartis.ru/ru/homepage.shtml. (дата обращения 03.11.2017).

Структура экономики. Швейцария. Справочник 2017. [Электронный ресурc] URL: https://www.sge.com/sites/default/files/cserver/publication/free/ihb-02-economic-structure-in-russian-s-ge.pdf (дата обращения 15.11.2017).

\section{References}

Avramenko S.L. (2003) SHvejcarskij federalizm na rubezhe stoletiya MGIMO Universitet. 177 s.

Belov N.I. (2014) Sovremennoe sostoyanie rossijsko-shvejcarskih torgovo-ehkonomicheskih otnoshenij // Rossijskij vneshneehkonomicheskij vestnik. № 12, S. 97-107.

Benediktes R., Kaelin L. (2013) Swiss Miracle?: Beyond Chocolate, Cheese and Banking// Foreign Affairs. April 9, 2013.

Dannye Banka Rossii [Электронный pecypc] URL: http://www.cbr.ru/statistics/?PrtID=svs (дата обращения 10.09.2018).

Degarden B. (2013) Fenomen bankovskoj sistemy SHvejcarii. Istoricheskie fakty i sovremennye tendencii razvitiya. Izbrannye lekcii Universiteta. 2013. Izd-vo Sankt-Peterburg SPbGUP. 45 s.

Evropejskaya integraciya (2011) (pod redakciej O.V. Butorinoj. Izdatel'skij dom "Delovaya literature". $720 \mathrm{~s}$.

Evropeyskiye pryamyye investitsii v Rossii. (2006). Pod redaktsiyey d.e.n. A. Kuznetsova. Moskva.

IMEMO RAN. 2006. 133 p.

Eurostat Newsrelease 201/2017 Foreign Direct Investment Statistics at the end of 2016. 21 December 2017 [Электронный ресурс] URL: https://ec.europa.eu/eurostat/ (accessed 12.10.2018).

Global Innovation Index 2018 Energizing the World with Innovation 11 edition. Cornell college of business, INSEAD, WIPO 2018463 р. [Электронный ресурc] URL:https://www.globalinnovationindex.org

Godovoj obzor ehkonomiki i osnovnykh napravlenij vneshneehkonomicheskoj deyatel'nosti SHvejtsarskoj Konfederatsii v 2016 godu. (2017) Bern aprel' 2017 g. 148 s.

Gosudarstva Al'pijskogo regiona i strany Benilyuks v menyayushchejsya Evrope (2009) (Pod redakciej SHvejcera V.YA.) M.: Iz-vo "Ves' Mir". 544 p.

Современная Европа, 2018, №6 
Inostranstvuyushchie investicii [Электронный ресурc] URL: https://www.kommersant.ru/doc/1883823 (accessed 12.10.2017).

Investitsii v Rossii. 2017: Stat. Sbornik. (2017) M. Rosstat. 188 p.

Investment Projects of Swiss Companies in Russia. North Caucasus Development Corporation. (2014) March 2014, 16 p.

Investitsionnyy portal regionov Rossii. [Электронный ресурc] URL:

https://www.investinregions.ru/succes (accessed 03.11.2017).

Issledovaniye investitsionnoy privlekatelnosti stran Evropy. Rossiya 2018 g. Ernst end Yang (2018) 8 s.

Optimizatsiya investitsionnykh svyazey sovremennoy Rossii. (2016) Pod redaktsiyey chlenakorrespondenta RAN A.V. Kuznetsova. Moskva. IMEMO RAN. 120 s.

Pryamyye inostrannyye investitsii v Rossiyu: regionalnyy aspekt. Analiticheskiy obzor 1 aprelya 2014. Natsionalnoye reytingovoye agentstvo 2014 g. 15 p.

Sajt kompanii “Novartis” [Электронный ресурс] URL: http://www.novartis.ru/ru/homepage.shtml. (accessed 03.11.2017).

Struktura ekonomiki. Spravochnik 2017. [Электронный pecypc] URL: https://www.sge.com/sites/default/files/cserver/publication/free/ihb-02-economic-structure-in-russian-s-ge.pdf (accessed 15.11.2017).

Swiss Federal Statistical Office. Statistical Data on Switzerland 2017. (2017) Neuchatel. March 2017, 52 p.

Swiss National Bank Data Statistics. International economic affairs. Direct investment abroad. 2016, 2016-12-16 [Электронный ресурс] URL:

https://data.snb.ch/en/topics/aube\#!/cube/fdiausbla?fromDate=2007\&toDate=2016\&dimSel=d0(T0,T1,RU,B 3,T2,T4,T5,T6.

Ventes en hausse pour les grandes societies Suisse en Russie. // Le Temps 2 Octobre 2016. [Электронный ресу] URL: http://www.letemps.ch/economie.2016/10/07venys-hausse-grandes-societes-suisse-russie (accessed 20.11.2017).

Yvonne Guo and Jun Jie Woo. Singapore and Switzerland: Secrets to Small State Success. (2016) World Scientific Publishing. $352 \mathrm{p}$.

World Investment Report 2018. Investment and New Industrial Policies. UNCTAD. N.Y., Geneva. (2018) 194 р. [Электронный ресурc] URL: www.unctad.org//fdistatistics).

\section{Swiss investment policy in Russia before and after sanctions}

Author. Trofimova O., Candidate of Economic Sciences, Senior Researcher of The Center of European Studies of Institute of World Economy and International Relations of Russian Academy of Sciences. Address: 23, ul. Profsoyuznaya, Moscow, Russia, 117 997. E-mail: olgatrofimova53@mail.ru

Abstract. The article focuses on specifics of Swiss investments in Russia, which were formed before the introduction of sanctions against Russia as well as after Switzerland joined them. The author studies a number of factors both objective and subjective, which have influenced the investment strategy, first of all concerning the structure of Swiss investments, their niche character and traditional specialization, sectoral orientation and regional distribution. The author integrates statistical data of Central Banks of Russia and Switzerland, international organizations and studies of Russian and foreign researchers, and shows the dynamics and changes of the existing Swiss investment structure in Russia and their inflow by selected groups. The article demonstrates in detail the evolution of the Swiss-Russian investment relations in the 2000s using the method of comparative analysis of data on different European countries with the purpose to fix particular periods characterized by their growth or fall caused by conjuncture and subjective factors such as sanctions. The author concludes that, despite the sanctions Russia remains in the sphere of Switzerland's interests. The flow of Swiss direct investment is growing and Swiss companies continue to invest in Russian economy using production localization in particular branches and Swiss technologies.

Key words: direct investments, Switzerland, investment cooperation, sanctions, investment structure, sectoral specialization, regional distribution.

DOI: http://dx.doi.org/10.15211/soveurope62018123133 